\title{
Implementation of digital media in higher education. An experience from the classroom
}

\section{Implantación de los medios digitales en la enseñanza superior. Una experiencia desde el aula}

DOI: $10.46932 / \mathrm{sfjdv2n3-054}$

Received in: May 1st, 2021

Accepted in: Jun 30th, 2021

\section{Isabel Legaz}

Associate Professor. Department of Legal and Forensic Medicine, Biomedical Research Institute (IMIB), Regional Campus of International Excellence "Campus Mare Nostrum", Faculty of Medicine, University of Murcia, (Murcia), Spain.

E-mail: isalegaz@um.es

\section{Aurelio Luna}

Full professor. Department of Legal and Forensic Medicine, Biomedical Research Institute (IMIB), Regional Campus of International Excellence "Campus Mare Nostrum", Faculty of Medicine, University of Murcia, (Murcia), Spain.

\begin{abstract}
The digital development of this century is transforming our society and, in parallel, the knowledge society. These new transmission platforms represent a different way of understanding the process of transmitting and receiving knowledge. The Wiki space is increasingly established in virtual higher education classrooms. The objective of this work was to implement the use of the Wiki space in the conventional teaching methodology of university studies and assess the degree of satisfaction of the student and its adequacy in the teaching process. A survey of 22 items was carried out to assess the opinion of 174 students regarding the use and capabilities of the Wiki tool. Our results show that $98.2 \%$ rated the use of Wiki space positively. $83.3 \%$ of the students were able to promote self-learning, and $73.0 \%$ considered this a helpful resource to promote the teaching-learning process. $65.2 \%$ considered that the use of ICTs in higher education should be increased. In conclusion, the use of Wiki in the higher education teaching classroom has gained significant acceptance by students who consider it an innovative experience that favors learning and the critical search for information, increasing the motivation for the subject.
\end{abstract}

Keywords: digital media, biochemistry, self-training, digital; teaching, Wiki space, collaborative work, criminology

\begin{abstract}
The digital development of this century is transforming our society and, in parallel, the knowledge society. These new transmission platforms represent a different way of understanding the process of transmitting and receiving knowledge. The Wiki space is increasingly established in virtual higher education classrooms. The objective of this work was to implement the use of the Wiki space in the conventional teaching methodology of university studies and assess the degree of satisfaction of the student and its adequacy in the teaching process. A survey of 22 items was carried out to assess the opinion of 174 students regarding the use and capabilities of the Wiki tool. Our results show that $98.2 \%$ rated the use of Wiki space positively. $83.3 \%$ of the students were able to promote self-learning, and $73.0 \%$ considered this a helpful resource to promote the teaching-learning process. $65.2 \%$ considered that the use of ICTs in higher education should be increased. In conclusion, the use of Wiki in the higher education teaching
\end{abstract}


classroom has gained significant acceptance by students who consider it an innovative experience that favors learning and the critical search for information, increasing the motivation for the subject.

Keywords: digital media, biochemistry, self-training, digital; teaching, Wiki space, collaborative work, criminology

\section{INTRODUCTION}

The development of new didactic strategies based on Information and Communication Technologies (ICTs) is the basis for developing the new digital education increasingly implemented in our society. The exponential digital development of this century is transforming our society and, in parallel, our knowledge society. The excellent reception of digital education lies mainly in the active role that the student acquires in the search for information adapted to her needs. This new social education supposes a different way of understanding the transmission and reception of knowledge where the classic relations between educator and student are changed.

The significant advantages that digital education presents are part of the great success it is having in our educational systems. This education allows for greater autonomy and greatly personalizes learning. Digital education allows a rapid evaluation of what has been learned, which allows the educator to detect deficiencies and develop corrective measures in real-time, which would allow a more educational and supervisory online evaluation, thus attending to the different educational needs. Collaborative work is one of the possibilities of digital education that allows information exchanges and synergies that feed digital knowledge.

In the new reorganization of the educational act, the role of the digital educator lies mainly in developing and properly organizing sequences of content appropriate to different levels and needs so that the student acquires digital knowledge clearly and efficiently, leaving the educator liberated within the classroom to serve their students. The teacher becomes a mere conductor and director of the educational process (educational coaching), as the prominent international universities and increasingly European universities are already betting on, with the development of virtual teaching methodologies in the form of "Massive Open Online Courses" (MOOCs) and "Open Course Ware" (OCW).

In this digital transition period in Spanish university education, the Wiki space in virtual classrooms is perhaps the most used digital educational tool. Wiki spaces are considered to stimulate the incremental creation of knowledge (Wager, 2004). It is a consolidated open editing tool in which content can be added and modified synchronously. Several authors highlight its usefulness since it improves the learning process, is modifiable and consists of flexible hours, improves group dynamics, allows continuous evaluation of the tasks that are carried out, serves as a space for communication and 
collaboration in the classroom, space to perform and present tasks, spaces for group projects (Lot, 2005; Adell, 2007).

The main objective of this work has been to implement the use of the Wiki space digital tool in the teaching methodology in higher education, assessing the degree of student satisfaction, the critical search for information, self-training, and adaptation in the teaching-learning process.2. Materiales $y$ métodos:

\subsection{STUDY POPULATION.}

In this study, 174 students belonging to the Degree in Biochemistry and Criminology at the University of Murcia participated. The mean age was $21 \pm 1.2$ years (mean $\pm \mathrm{SD}$ ), participating in this study voluntarily. Of the total number of students, $36.2 \%$ correspond to men, while $63.2 \%$ correspond to women.

\subsection{OPINION POLLS.}

A survey made up of 22 items was designed to assess the opinion of the students regarding the use and capacities of the Wiki tool. The responses of 18 items corresponded to dichotomous quantitative variables (Yes / No), except for items 9, 17, 19, and 22, whose responses vary from one to five, with the value of one being disagreement and the value five agreeing.

The degree of student satisfaction was assessed through item 22, establishing two groups for our study; "Very satisfied" to those who answered a value of four or five, and as "not very satisfied" to those who chose a value between 1 and 3 (both inclusive).

\subsection{STATISTICAL ANALYSIS OF THE DATA.}

Sociodemographic data were analyzed using the SPSS 19.0 statistical package. Variables between groups were compared using the two-tailed Fisher's exact test and the "Pearson $\mathrm{X}^{2 "}$ test. "P-value" less than 0.05 was considered statistically significant.

\section{ANALYSIS AND RESULTS}

\subsection{STUDENTS' PREVIOUS KNOWLEDGE ABOUT WIKI SPACES.}

A total of $62.1 \%$ of the students surveyed did know the Wiki tool (Figure 1A), but $77 \%$ have never used it (Figure 1B), although 53.4\% of them did know its usefulness (Figure 1C). It should be noted that 
$78.7 \%$ of university students state that they have never used Wiki spaces during their entire university training (Figure 1D).

Figure 1. Students' previous knowledge about Wiki spaces. (A) Did you know Wiki spaces ?; (B) Have you ever used Wiki spaces ?; (C) Do you know the usefulness of the Wiki ?; (D) Has any university professor used it before?

A

B

C

D
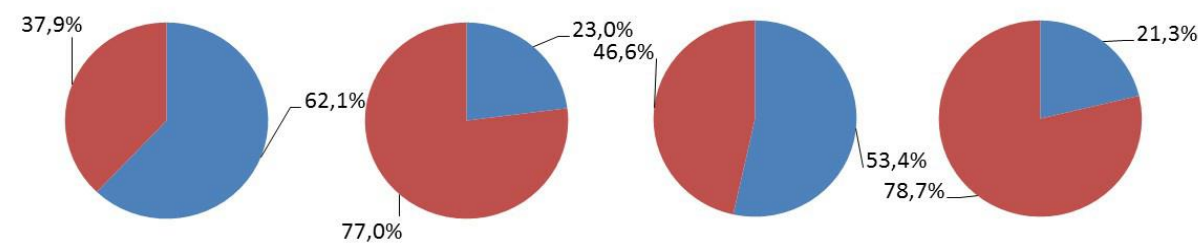

sI

NO

However, most of the students who were aware of the existence of Wiki spaces mainly were through the Internet (Figure 4). In addition, it was observed that men had more excellent knowledge about this tool than women $(73 \%$ vs. $55.5 \%, \mathrm{P}=0.024)$

Figure 2. Analysis of the primary sources of information on Wiki spaces.

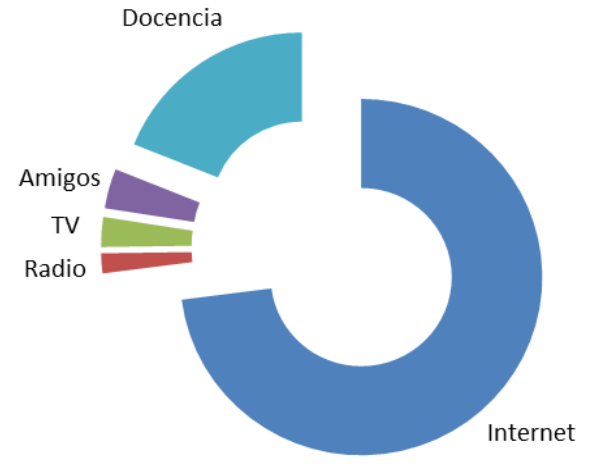

\subsection{ANALYSIS OF THE DEGREE OF STUDENT SATISFACTION.}

The previous teaching instructions for the subsequent management of the Wiki space were wellvalued by most of the students (97\%), and only $2.3 \%$ found some kind of difficulty (Figure 3). Most of the students $(94.3 \%)$ liked learning to use a Wiki space (Figure 3B), especially women with 98.2\% (P= 0.005). The teaching staff got $80.5 \%$ of the students to visit the contributions proposed by their classmates (Figure 3C). 
Figure 3. Analysis of the degree of student satisfaction towards Wiki spaces. (A) Were the instructions sent by the teacher clear?; (B) Did you like learning how to use a Wiki ?; (C) Did you visit the contributions of the rest of the students to the Wiki space?

A

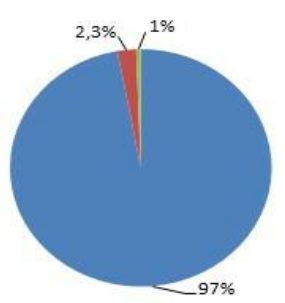

B

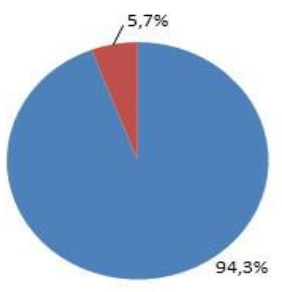

$\square$ No $\square$ Ns/NC

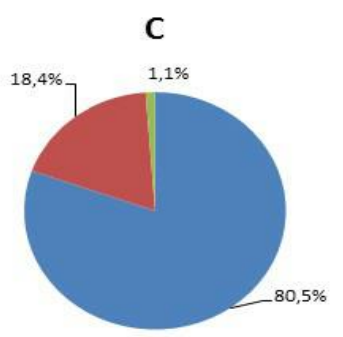

\subsection{WIKI SPACE AS A TOOL FOR PROMOTING SELF-LEARNING, MOTIVATION, AND INTEREST IN TEACHING CONTENT.}

The use of Wiki spaces incorporated into traditional regulated teaching has made it possible to promote self-learning in $83.3 \%$ of the students. $63.8 \%$ of the students stated that thanks to this experience, their motivation and interest in the teaching content of the subject increased (Figure 4A-B), its habitual use in class being considered beneficial (73.0\%) to favor teaching processes -learning (Figure 4C).

Figure 4. Wiki space as a tool for promoting self-learning, motivation, and interest in teaching content. (A) Does this resource facilitate your self-learning?; (B) Did you manage to enhance motivation and interest in teaching content? (C) Do you consider its habitual use in helpful classes to facilitate the teaching-learning processes?

A

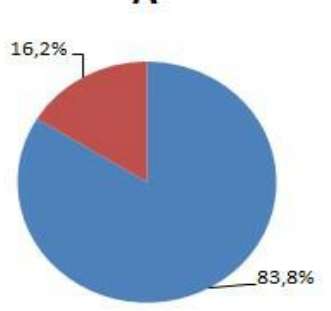

B

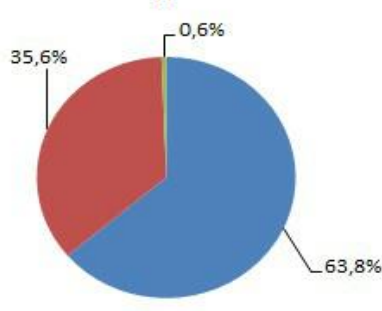

C

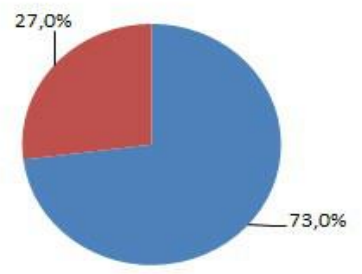

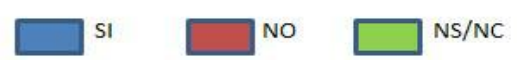

\subsection{WIKI SPACE AS A TOOL TO TRANSMIT KNOWLEDGE}

The students stated that using this teaching resource allowed them to deepen and assimilate the contents (73\%) adequately, and $93.1 \%$ of the students state that if they were asked about the practice carried out after a while, they would remember its content (Figure 5A). $73.6 \%$ would have liked to 
participate in a Wiki space for another university degree subject (Figure 5B). $82.2 \%$ of the surveyed students affirmed that the teacher, using this resource, achieved his purpose of transmitting the subject in an empathetic and straightforward way (Figure 5C).

Figure 5. Analysis of the assessment of the reception and transmission of teaching knowledge using Wiki space. (A) Was this web helpful resource to deepen and assimilate the subject?; (B) Would you have liked to participate in a Wiki space for another subject ?; (C) Do you think that the teacher using this resource achieved his purpose of transmitting the matter in an empathetic and straightforward way?.

A

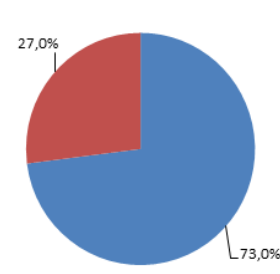

B

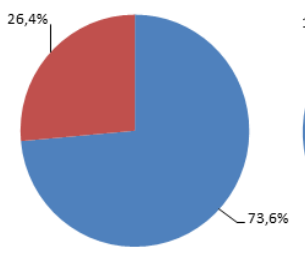

SI
C

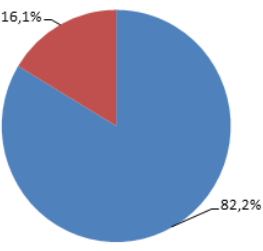

\subsection{ANALYSIS OF THE DEGREE OF STUDENT SATISFACTION WITH THE USE OF WIKI} SPACES IN HIGHER EDUCATION.

When the degree of satisfaction of the students was analyzed, it was observed that $65.5 \%$ of the students responded in a beneficial way to this activity, while 33.9\% felt little satisfied (Figure 6).

Figure 6. Analysis of the degree of student satisfaction with the use of Wiki spaces in higher education. Blue color, very satisfied students. Red color, dissatisfied students.

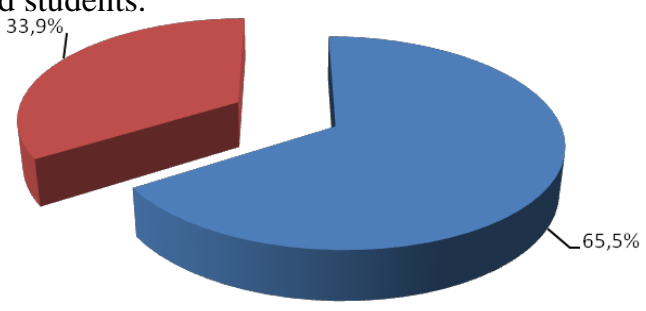

Very satisfied students consider that the teacher using this resource has facilitated their selflearning (93.9\%) (Figure 7A). In this group, motivation and interest in the subject were enhanced (76.3\%) (Figure 7B). All the students stated that the transmission of knowledge is carried out in a simple and empathetic way through Wiki spaces (Figure 7C). 
Figure 7. Analysis of the degree of satisfaction of the students about the use of Wiki spaces in higher education (A) Do you think that the teacher using this resource facilitates your self-learning?; (B) Did you manage to enhance motivation and interest in the subject ?; (C) Do you think that the teacher using this resource achieved his purpose of transmitting the matter in a simple and empathetic way? ${ }^{\mathrm{a}} \mathrm{OR}=9,855 ; 95 \% \mathrm{CI}: 3,699-26,256$. ${ }^{\mathrm{b}} \mathrm{OR}=4,903 ; 95 \% \mathrm{CI}: 2,483-9,684$. ${ }^{\mathrm{c}} \mathrm{OR}=4,590 ; 95 \% \mathrm{CI}: 1,952-$ 10,794 .
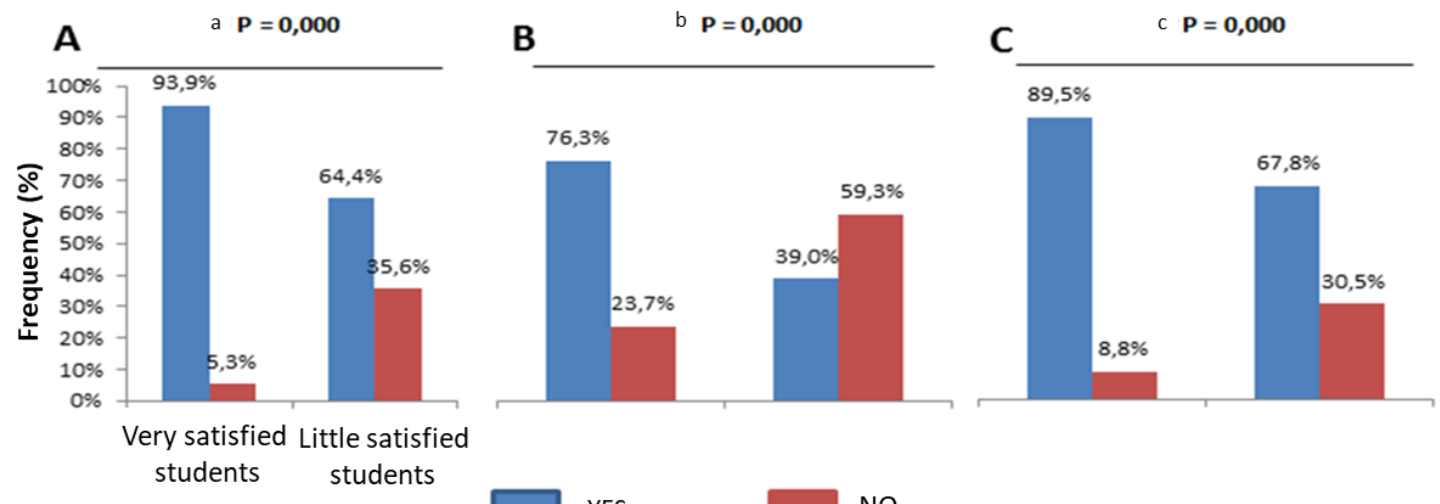

YES

NO

This teaching resource was helpful for $82.5 \%$ of the highly satisfied students and $54.2 \%$ of the dissatisfied students deepen and assimilate the subject (Figure 8A). An approximately similar value was obtained when asking if they would have liked to participate during their undergraduate studies in a Wiki space for another subject (Figure 8B). In addition, $78.9 \%$ of the satisfied students and $62.7 \%$ of the dissatisfied students consider their habitual use in practical classes to facilitate the teaching-learning processes (Figure 8C).

Figure 8. Analysis of the degree of student satisfaction with the use of Wiki spaces in higher education. (A) Was this web resource useful to you to deepen and assimilate matter?; (B) Would you have liked to participate in a "Wiki" space for another subject ?; (C) Do you consider its habitual use in class useful to facilitate the teaching-learning processes? ${ }^{\mathrm{g}} \mathrm{OR}=3,966 ; 95 \&$ CI: $1,962-8,016 .{ }^{\mathrm{f}} \mathrm{OR}=4,500 ; 95 \% \mathrm{CI}: 2,194-9,228 .{ }^{\mathrm{h}} \mathrm{OR}=2,230 ; 95 \%$ CI: $1,114-4,462$.

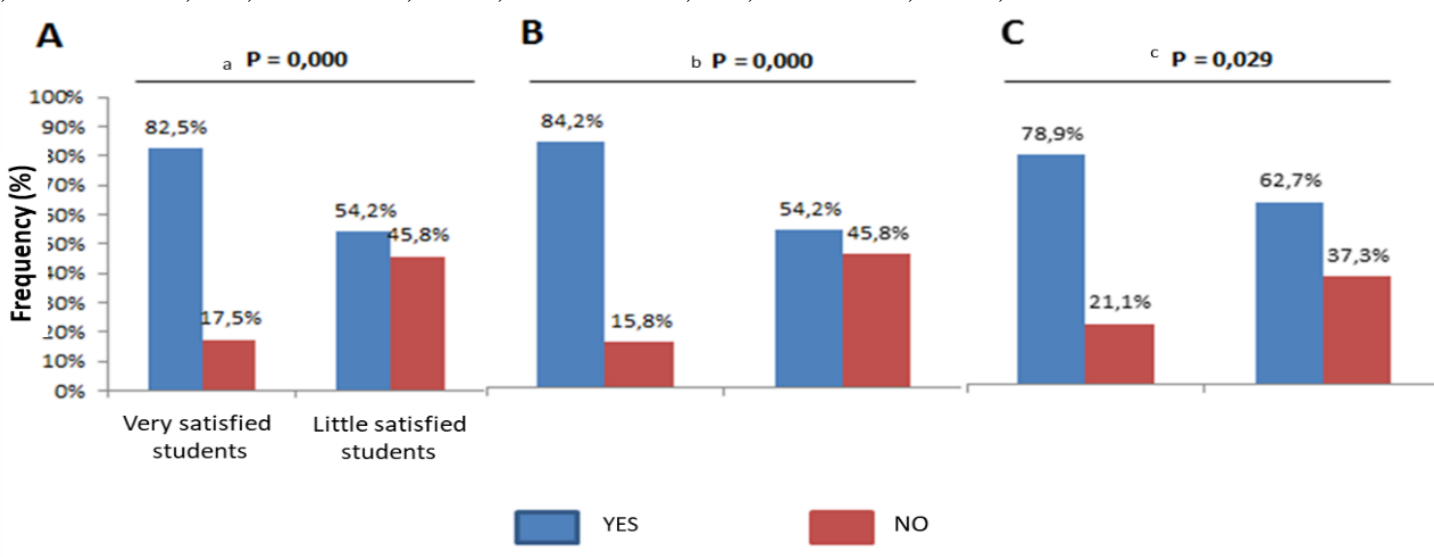

\section{DISCUSSION AND CONCLUSIONS.}

In this study, we have implemented and assessed the use of Wiki digital spaces as a platform for teaching innovation in different subjects in university education to promote self-learning, motivation, and 
interest in teaching content, as well as the acquisition of the student's knowledge and use of new ICT technologies in order to facilitate the teaching-learning process.

The use of this teaching innovation tool allows an adaptation to the new competencies required by the EHEA (Benito \& Cruz, 2005), which, together with the psycho-pedagogical tools of «Brainstorming», allow the teacher to transmit information in an empathetic and straightforward way (Legaz \& Luna, 2014; Morales \& Legaz, 2021).

In another study, they observed that $95 \%$ of their surveyed students had not used this educational resource and, curiously, in our study, we have found similar results, since most of the students stated that they were not used to participating in this type of digital tool during their training. This circumstance could be due to the teachers' ignorance of these digital resources (Mancho, Porto \& Valero, 2009).

The Wiki topics were made on teaching content that shows difficulty on the part of the students to reinforce learning, motivation, and interest on the part of the students. Therefore, our results corroborate our expectations, showing how it helped most students understand complicated content. In general, the students appreciated the use and effort made by the teaching staff to implement this resource.

An educational project with Wiki technologies developed by the University of Cádiz consisted of creating a Wiki by the students for the "Functional Programming" subject of the Computer Engineering degree (Palomo, Medina, Rodríguez, \& Palomo, 2012). Its development helped the 40 students who participated in it to pass the subject. Wiki in teaching was valued at 4.5 out of 5 points and, its authors affirm that they remained highly motivated and involved in the project throughout the experience.

When the student ceases to be a passive agent, a receiver of information, and becomes an active agent, acquiring a leading role in their learning process, students' motivation towards classroom activity improves (Villarroel, 2007). This statement can be confirmed in our study. Wiki as a teaching resource enhanced motivation and interest in the subject in most students regardless of gender. Wiki shows how beneficial innovation in the classroom is for students to acquire new knowledge through new ways of transmitting information, moving away from classical learning systems, based mainly on acquiring unidirectional theoretical knowledge in the traditional classroom.

On the other hand, Santos, Galán, \& Del Olmo (2005) from the University of Burgos, in their subject "New Technologies and Business" of the Computer Engineering Degree, developed an innovation experience in which students were encouraged to participate in the construction of an educational Blog in which both students and teachers published content. After the experience, we observed that using this type of resources favored developing skills such as teamwork, the capacity for analysis and synthesis, communication, and research. 
In addition, they carried out a study in which they wanted students to learn to use logbooks (blogs) as didactic resources for future education professionals' training to become active agents in their process. of knowledge construction. The results obtained confirm that the use of blogs in particular, and that of ICTs in general, constitute an adequate and helpful teaching tool for students to develop an active role during their training process, as our results also corroborate (López \& Ballesteros, 2012).

After each student's contribution to the Wiki, the students had at their disposal both the comments of their classmates and the digital content proposed by each of them so that they could view the content contributed by all. $80.5 \%$ of the surveyed students claim to have visited the comments proposed by their classmates. Those students can read the work of the rest of their classmates on a single platform, generating a particular competition between them that can increase the quality of the contributions (Barreiro, 2011).

One of the main limitations that we have found in our study has been the limited time that has been had to implement this teaching resource in more undergraduate and postgraduate subjects taught by the Department of Social Health Sciences. On the other hand, the students stated that this teaching space could be improved by creating discussion forums on different topics and increasing their use throughout the course and the number of topics. A high percentage of students consider that the ICTs by university teaching staff should be increased during or in addition to lectures.

The teaching team has stated that the balance has been positive concerning the acquisition of knowledge by the students and an increase in the follow-up of the classes. However, for teachers, the development and use of these new technologies required a high effort and dedication in their initial moments. Therefore, the teachers considered that the tool has much potential as a start in digital teaching, developing collaborative methodologies type "b-learning" in higher education that improve current methodologies in the classroom.

Therefore, we can conclude that the high degree of satisfaction of university students when using Wiki spaces has allowed them to develop capacities such as critical search and the ability to synthesize information, facilitating self-learning and favoring the teaching-learning process by what new digital tools must be incorporated into the teaching field of higher education. 


\section{REFERENCES}

1 Adell J. (2007). Wikis en educación. In J. Cabero \& J. Barroso (Eds.), Posibilidades de la teleformación en el espacio europeo de educación superior (pp. 323-333). Granada: Editorial Octaedro Andalucía. https://bit.ly/2G7f3RC

2 Barreiro, E. (2011). Del blog al entorno personal de aprendizaje. Experiencias educativas en las aulas del siglo XXI: innovación con TIC (pp. 241-243). Editorial Ariel, S.A. https://bit.ly/2IAd8tV

3 Benito A., \& Cruz, A. (2005). Nuevas claves para la docencia universitaria en el Espacio Europeo de Educación Superior. Revista de Enseñanza Universitaria 27, 103-104. Madrid: Nancea, S.A. Ediciones.

4 Legaz, I., \& Luna, A. (2014). Experiencia de innovación educativa con Brainstorming en la Universidad de Murcia. In Campus Mare Nostrum (Eds.), II Congreso Internacional de Innovación Docente (pp. 146-155). http://hdl.handle.net/10317/4016

5 López-Meneses, E., \& Ballesteros-Regaña, C. (2012). Innovación didáctica, tecnología 2.0 y blogs: una experiencia práctica con estudiantes universitarios. I Congreso Virtual Internacional sobre Innovación Pedagógica y Praxis Educativa Innovagogia 2012. (pp. 582-590). http://www.upo.es/ocs/index.php/innovagogia2012/Iinnovagogia2012/paper/view/59

6 Lot C. (2005). Introduction to the Wiki. Distance Learning Systems. Center of Distance Education.

7 Mancho, G., Porto, M., \& Valero, C. (2009). Wikis e innovación docente. Revista de educación a distancia. Monográfico XII: Wiki y educación superior en España (I parte) https://bit.ly/2KSVXSG

8 Morales, R., \& Legaz I. (2021). Use of mobile devices in medical education. South Florida Journal of Development 2.2 (pp. 1230-1240).

8 Palomo, M., Medina, I., Rodríguez, J., \& Palomo, F. (2012). Wikis en docencia: una experiencia con WikiHaskell y StatMediaWiki. Revista de Universidad y Sociedad del Conocimiento (RUSC). 9(1), 258277. DOI: http://dx.doi.org/10.7238/rusc.v9i1.1035

9 Santos, I., Galán, M., \& Del Olmo, R. (2005). Nuevas estrategias de enseñanza: experiencia con Weblogs. IX Congreso de Ingeniería de Organización. (pp. 120) https://bit.ly/2rC4DoF

10 Villarroel J. (2007). Usos didácticos del wiki en educación secundaria. Ikastorratza, e-Revista de Didáctica 1, 1-7. https://bit.ly/2jStYGF

11 Wagner C. (2004). Wiki: a technology for conversational knowledge management and group collaboration. Communications of the Association for Information Systems. (13)XIX, 265- 289. https://bit.ly/2IeWGvP 